\title{
BMJ Open Distance as a barrier to obstetric care among indigenous women in Panama: a cross-sectional study
}

\author{
Paloma Acevedo, ${ }^{1}$ Sebastian Martinez (i) , ${ }^{1}$ Leonardo Pinzon, ${ }^{2}$ \\ Emmanuelle Sanchez-Monin, ${ }^{2}$ Solis Winters ${ }^{1}$
}

To cite: Acevedo P, Martinez S, Pinzon L, et al. Distance as a barrier to obstetric care among indigenous women in Panama: a cross-sectional study. BMJ Open 2020;10:e034763. doi:10.1136/ bmjopen-2019-034763

- Prepublication history and additional material for this paper are available online. To view these files, please visit the journal online (http://dx.doi org/10.1136/bmjopen-2019034763).

Received 07 October 2019 Revised 03 January 2020 Accepted 24 January 2020

Check for updates

(C) Author(s) (or their employer(s)) 2020. Re-use permitted under CC BY-NC. No commercial re-use. See rights and permissions. Published by BMJ.

${ }^{1}$ Office of Strategic Planning and Development Effectiveness, Inter-American Development Bank, Washington, DC, USA

${ }^{2}$ Social Protection and Health Division, Inter-American Development Bank, Washington, DC, USA

Correspondence to Dr Sebastian Martinez; SMARTINEZ@iadb.org

\section{ABSTRACT}

Objectives We assess the relationship between distance to a woman's assigned health clinic and obstetric care utilisation.

Design We employ a cross-sectional study design using baseline data from the evaluation of a conditional cash transfer programme to promote greater utilisation of maternal and infant health services. Data were collected between December 2016 and January 2017.

Setting The study is conducted in Ngäbe Buglé, the largest of Panama's three indigenous territories, where maternal mortality is three times the national average. Participants We analyse a representative sample of 1336 indigenous women with a birth in the 12 months prior to the survey.

Primary and secondary outcome measures Primary outcomes include obstetric care utilisation measures for prenatal, childbirth and postpartum events. Secondary outcomes include reasons for not receiving prenatal care, alarming symptoms, child weight at birth and stillbirths or miscarriages.

Results Compared with women in closest geographic proximity to a health centre (top quintile, Q1), women who lived farthest from a health centre (bottom quintile, Q5) had significantly lower obstetric care utilisation outcomes for critical prenatal, childbirth and postpartum events. Mothers in $Q 5$ were 36 percentage points less likely to have had at least one prenatal care appointment in a hospital, health centre or clinic compared with mothers in Q1 $(p<0.01)$, and 52 percentage points less likely to attend an institutional first appointment $(p<0.01)$. The gap in institutional delivery and postnatal care between mothers in $Q 1$ and $Q 5$ was about 35 percentage points $(p<0.01)$. All utilisation outcomes were negatively correlated with distance, and differences in obstetric care utilisation persisted even when controlling for household wealth, maternal age and maternal education.

Conclusion Distance is an important barrier to obstetric care utilisation, with women in more distant locations suffering significantly lower use of prenatal, childbirth and postpartum care compared with women in closer vicinity to a health establishment. Expanding the supply of healthcare and implementing demand side incentives to promote the use of health services in remote communities are relevant policies to reduce disparities in obstetric care utilisation.

Trial registration number AEA Registry (RCT ID AEARCTR-0001751).

\section{Strengths and limitations of this study}

We implement a novel approach to calculating distance as a barrier to care.

- We analyse rich health utilisation data for a representative sample of 1336 indigenous mothers.

- Limitations of the study include analysis of selfreported utilisation outcomes and a remote study area.

\section{INTRODUCTION}

Disparities in access to healthcare and its implications for maternal and child health are a concern worldwide. The Sustainable Development Goals include a target to 'reduce the global maternal mortality ratio to less than 70 per 100000 live births by 2030, with no country having a maternal mortality rate of more than twice the global average'. 'Though substantial progress was made between 1990 and 2015, with a decline in maternal mortality of about $44 \%$, there is still a far way to go to achieve this target. In 2015, 303000 women died from pregnancy-related causes, 2.7 million babies died during the first 28 days of life and 2.6 million babies were stillborn. ${ }^{2}$ These deaths, most of which could have been prevented, reflect inequalities in access to health services and income gaps. Developing countries account for $99 \%$ of all maternal deaths globally and have a maternal mortality rate of 239 per 100000 live births-almost 20 times higher than in developed countries (12 per 100000$)^{1}$

Indigenous populations are particularly vulnerable. In Latin America and the Caribbean, the countries with thelargest populations of indigenous people and Afro-descendants have the highest maternal mortality rates. Within countries, the maternal mortality rate among indigenous women is significantly higher than among non-indigenous women. According to the World Health Organisation (WHO), indigenous women in Latin America 
are three times more likely to die from causes related to pregnancy and childbirth than non-indigenous women living in the same communities. ${ }^{3}$ Women living in rural areas and in low-income communities are also disproportionally affected. ${ }^{1}$

Prenatal care during pregnancy, skilled care during childbirth and support in the weeks after childbirth can be the difference between life and death for both the mother and the newborn. Nearly $75 \%$ of all maternal deaths are due to severe bleeding, infections, preeclampsia or eclampsia, complications during delivery and unsafe abortions-conditions that have well-known methods for prevention and management. ${ }^{1}$ In addition to increased risk of death, inadequate prenatal care has been linked to poor birth outcomes, including low birth weight and preterm birth, which have lifelong effects on child development. ${ }^{45}$

Though the importance of prenatal care is well known, only $64 \%$ of pregnant women globally receive at least four prenatal care visits- the amount recommended by the WHO. ${ }^{1}$ In low-income countries, the rate is only $40 \%$, and in rural areas and poorer communities, utilisation is much lower. ${ }^{2}$ Many studies in developing countries have identified an inverse relationship between distance to a health facility and the utilisation of health services. ${ }^{6-12}$ In a systematic review of 108 studies, $77 \%$ identified a distance decay association, where patients living further away from healthcare facilities had worse health outcomes than those who lived closer. ${ }^{13}$

For indigenous women and children in Panama, one of Latin America's highest per-capita income countries, the disparities in health access and health outcomes are equally stark. This study assesses the relationship between distance to a health clinic and the utilisation of obstetric care among households in Ngäbe Buglé, Panama's largest indigenous territory by both geographic extension and population. We analyse an original maternal-child health survey with rich healthcare utilisation data for a representative sample of 1336 indigenous women with children younger than 12 months and use precise geo-location data to accurately measure the travel distance between households and their assigned health clinic.

\section{METHODS}

\section{Study area}

Ngäbe Buglé, with 156747 inhabitants according to the 2010 Census, is the largest of Panama's three indigenous territories and has the highest multidimensional poverty index score of all the regions in the country (0.469)..$^{14}$ Geographically, it is very remote and comprised mostly of small and dispersed communities. Its mountainous terrain, numerous rivers and remote coastal geography make travel between communities and outside the region very difficult. ${ }^{16}$

Maternal and infant mortality and morbidity in Panama's indigenous territories are much higher than the rest of the country. Ngäbe Buglé has an infant mortality rate of
21.4 per 1000 live births compared with the national rate of 13.9 , and a maternal mortality rate more than three times the national average $\left(162.5,49.2\right.$, respectively). ${ }^{17}$ Prenatal care utilisation is also much lower. A qualitative study in Ngäbe Buglé identified lack of transportation, high transportation costs, high opportunity costs, lack of confidence in the quality of care, discordance between cultures and lack of empowerment as important barriers to prenatal care utilisation in the region. ${ }^{18}$

\section{Data}

We used baseline data from the evaluation of a conditional cash transfer programme implemented in Ngäbe Buglé to promote greater utilisation of maternal and infant health services. One thousand five hundred and forty-seven communities in Ngäbe Buglé were identified using the 2010 Census and all but six, which were part of an implementation pilot, were included in the sampling frame. Eight pairs of communities were very similar and geographically close to each other, therefore, for the purpose of the sampling, each pair was combined into one community to avoid contamination.

Of the eligible communities, a representative random sample of 304 communities was selected for the study. The sampling design was probabilistic, stratified and conducted in three stages. In the first stage, communities were grouped into 27 'population groups' (PG), each of which was covered by a distinct health service provider. PGs were then stratified by size (greater or smaller than the median) and seven PGs were randomly selected per strata. In the second stage, communities in the selected PGs were clustered into a 'central community cluster' (CCC). Each CCC was comprised of one main community, the 'central community' (CC) and one or more smaller and more disperse communities, the 'peripheral communities' (PC), which were affiliated with the CC for provision of health services. A random sample of 150 CCCs, weighted by population size, was selected. In the final stage, the CC and one of its PC, in each of the 150 CCCs, were randomly selected (weighted by population), resulting in a total of 300 communities. Of these, four were among those combined to avoid contamination, so according to the Census, 304 communities in total were selected.

The baseline survey was conducted between December 2016 and January 2017 using Computerised Assisted Personal Interviews technologies. Of the 304 communities in the sample, 302 were successfully reached. The average size of each community was 163 people. All households with children younger than 12 months in each community were interviewed. Mothers were asked questions related to prenatal care, childbirth and postpartum care and their responses were recorded. One thousand three hundred and thirty-six mothers, in 274 communities and 1314 households, completed the survey and had a child younger than 12 months old. In the 28 remaining communities, there were no children younger than 12 months. 


\section{Obstetric care}

The objective of this study is to understand the relationship between distance to a health facility and obstetric care utilisation before, during and after pregnancy. The primary outcomes of interest include the following utilisation measures as reported by the study subject in the baseline survey for the pregnancy of her child younger than 12 months old.

- Total number of prenatal appointments.

- Prenatal care, equal to 1 if mother went to at least one prenatal care appointment in a hospital, centre, or clinic and 0 otherwise.

- Institutional first prenatal appointment, equal to 1 if first appointment was in a hospital, centre, or clinic and was attended by a doctor or nurse and 0 otherwise.

- Number of weeks of pregnancy at first prenatal appointment.

- Early and institutional first prenatal appointment, equal to 1 if first appointment was institutional and before 12 weeks of pregnancy and 0 otherwise.

- Additional prenatal appointments, equal to 1 if mother went to another appointment after the first and 0 otherwise.

- Institutional additional prenatal appointments, equal to 1 if additional appointments were in a hospital or health centre and attended by a doctor or nurse and 0 otherwise.

- Institutional delivery, equal to 1 if the mother gave birth in a hospital or health centre and was attended by a doctor or nurse and 0 otherwise.

- Postnatal care, equal to 1 if mother had a postnatal appointment within 2 days of childbirth and 0 otherwise.

- Institutional postnatal care, equal to 1 if postnatal appointment was in a hospital or health centre and was attended by a doctor or nurse and 0 otherwise.

- Neonatal care, equal to 1 if child had a neonatal exam within 2 days of birth and 0 otherwise.

- Institutional neonatal care, equal to 1 if neonatal exam was in a hospital or health centre and was attended by a doctor or nurse and 0 otherwise.

In addition to these utilisation measures, we analysed secondary outcomes, including reasons for not receiving prenatal care, alarming symptoms during pregnancy, child weight at birth and percentage of stillbirths or miscarriages. All secondary outcomes were self-reported by mothers.

\section{Distance calculation}

All communities in Ngäbe Buglé were assigned to one of 13 public health centres located in the territory. We calculated the distance between households and their assigned health centre using Quantum Geographic Information System (QGIS) 2.18.1. First, we identified Ngäbe Buglé on Open Street Maps and downloaded a shapefile with the corresponding line network. While roads made up the vast majority of the network, the shapefile also included other polylines, such as rivers, canals, walls, pipelines, bridges and fences, among others. We kept all polylines, regardless of their type, in our calculation. We did this for two main reasons: (1) all the households are in very remote areas with a limited road network, so it is plausible that mothers travelled by water (river or canal) to reach their appointments, and (2) distances calculated from routes that follow a river, canal, fence, etc. rather than a road are likely to be closer to the true distance than the alternative option of using a linear path.

After creating three shapefiles with households, health centres and the road network, respectively, we used the QGIS Python Application Programming Interface (PyQGIS) to calculate the shortest route between each household and its assigned health centre. All overlapping lines were broken at the point of intersection. The shortest path was determined using the Dijkstra algorithm. ${ }^{19} 20$ In a few cases where the calculated routes appeared to be extremely unlikely, small gaps between road/line segments were manually connected and the routes were re-calculated. Given most households and health centres were not directly connected to any roads in the network, linear distances between the household or health centre and the edge of the calculated route were computed. The distance of the entire route, from the household to the health centre, was measured in kilometres. Route distances were then separated into quintiles, with average distances of 4.5, 12.4, 17.6, 24.9 and $50.4 \mathrm{~km}$, respectively. Five households missing distance information were excluded from the analysis. A map of all the routes is shown in figure 1.

\section{Covariates}

Wealth, age, education, number of pregnancies and empowerment are included as covariates in our regression models. Household wealth is based on self-reported data on asset ownership and housing characteristics such as floor, roof and wall materials, toilet facilities, source of drinking water, trash disposal, fuel, lighting, electricity and type of tenancy. These data were reduced into a wealth index score using principal component analysis (PCA). Mother's age (years), education (years) and number of pregnancies were self-reported. Empowerment is a measure of a mother's control over household decisions surrounding clothing, child education and health, finances, employment, contraception and obstetric care. An empowerment index from 0 to 1 was generated, representing the proportion of decisions the mother made out of 15 total categories.

\section{Statistical analysis}

We assessed the relationship between utilisation of obstetric care and distance by comparing mean differences in outcomes across distance quintiles. Using the computed distance for each route, we created distance quintiles in Stata 15, where Quintile 1 (Q1) corresponds to mothers in the closest $20 \%$ of households and Quintile 5 (Q5) to the furthest 20\%. We analysed gaps in obstetric care between the top and bottom quintiles, in addition to 


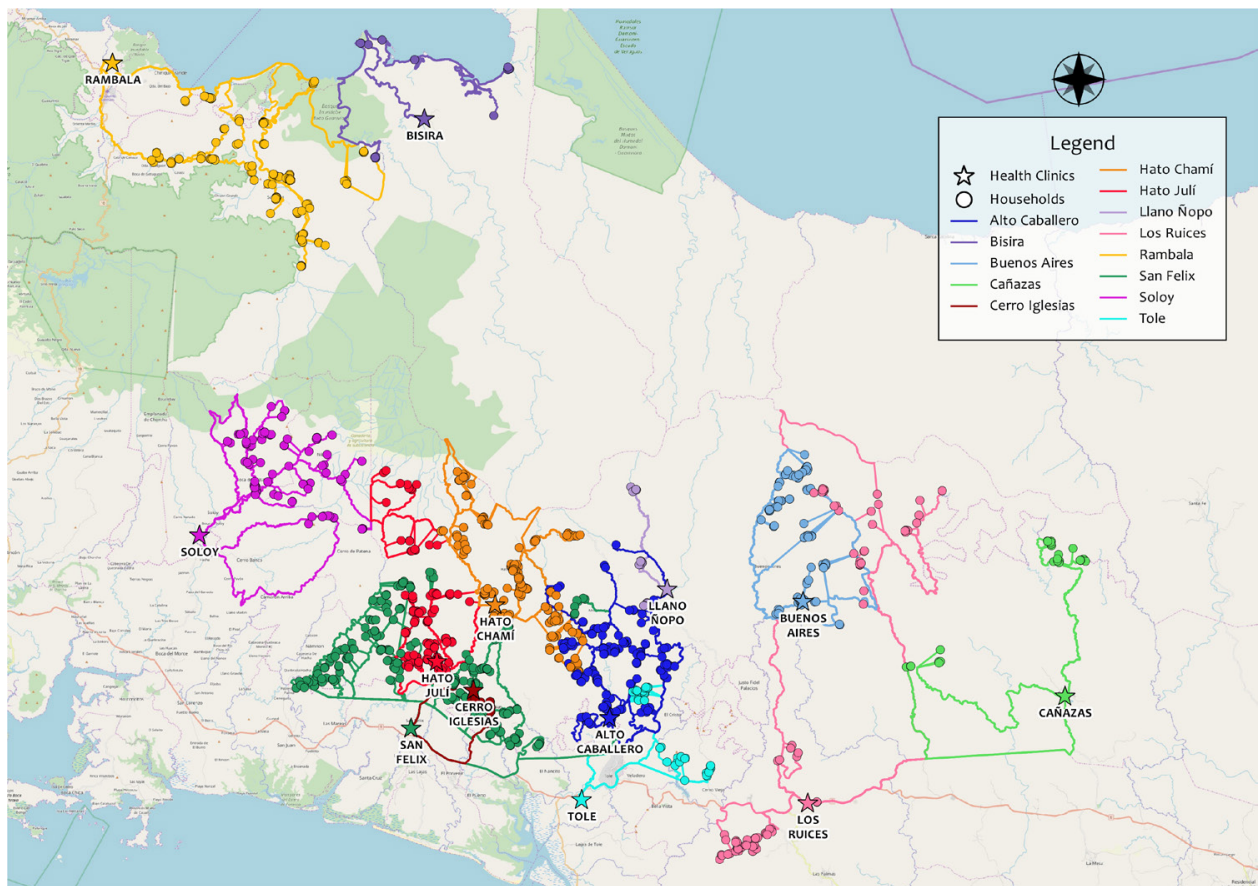

Figure 1 Computed routes between households and their assigned health clinics in Ngäbe Buglé, Panama.

gradients in healthcare utilisation across all five quintiles. Additionally, we conducted regression analysis to adjust for sociodemographic factors that may influence obstetric care outcomes. We ran an Ordinary Least Squares (OLS) regression model, specified as follows, for all outcomes:

$$
Y_{i}=\alpha+\sum_{k=2}^{5} \beta_{k} Q_{k i+} X_{i}+\varepsilon_{i}
$$

where $Y_{i}$ is a obstetric care outcome for mother $i, Q_{k i}$ is a binary variable for the $k$ th quintile of the distance distribution (where $Q_{1}$ is the omitted reference category), $\beta_{k}$ represents the difference in the average outcome obtained by the mothers in quintile $k$ with respect to the average outcome in $Q_{1} . X_{i}$ is a vector of controls for household wealth, mother's age (years), mother's education (years), number of pregnancies and mother's empowerment. In the case of categorical outcomes, the OLS regression estimates a linear probability model where $\beta_{k}$ is the probability of $Y=1$ for mothers in distance quintile $Q_{k}$ with respect to $Q_{1}$. Survey sampling design, including sample weights and clustering effects, was used for all analyses.

\section{Patient and public involvement}

Patients were not involved in the design, conception, planning, or conduct of this study.

\section{RESULTS \\ Descriptive statistics}

Descriptive statistics for the 1336 mothers in our sample are presented in table 1 . At the time of the survey, mothers were 26 years old, on average, and had completed 5 years of education. Only one mother was employed. Eightyfour per cent were married and the average number of

\begin{tabular}{|c|c|c|c|c|c|c|}
\hline & \multicolumn{3}{|l|}{ All } & \multirow{2}{*}{$\begin{array}{l}\text { Closest 20\% (Q1) } \\
\text { Mean }\end{array}$} & \multirow{2}{*}{$\begin{array}{l}\text { Furthest 20\% (Q5) } \\
\text { Mean }\end{array}$} & \multirow{2}{*}{$\begin{array}{l}\text { Q5-Q1 } \\
\text { Difference }\end{array}$} \\
\hline & $\mathbf{n}$ & Mean & SE & & & \\
\hline Age (years) & 1336 & 26.050 & 8.011 & 25.397 & 26.456 & 1.059 \\
\hline Education (years) & 1336 & 5.775 & 3.899 & 7.017 & 4.893 & $-2.124^{\star \star}$ \\
\hline Wealth (PCA score) & 1336 & -0.378 & 2.007 & 0.621 & -1.137 & $-1.758^{\star *}$ \\
\hline Employed (\%) & 1266 & 0.001 & 0.028 & 0.005 & 0.000 & -0.005 \\
\hline Married (\%) & 1336 & 0.843 & 0.364 & 0.854 & 0.842 & -0.012 \\
\hline Number of pregnancies & 1336 & 3.577 & 2.438 & 3.217 & 3.745 & $0.529^{*}$ \\
\hline Empowerment (\%) & 1336 & 0.521 & 0.278 & 0.537 & 0.504 & -0.032 \\
\hline
\end{tabular}

Means and standard errors (SE) are estimated considering survey sampling design, including sample weights and clustering effects. ${ }^{*} \mathrm{p}<0.05,{ }^{* *} \mathrm{p}<0.01$.

$\mathrm{PCA}$, principal component analysis; $\mathrm{Q}$, quintile. 
Table 2 Gaps in obstetric care by distance. Differences in simple means

\begin{tabular}{|c|c|c|c|c|c|c|}
\hline & \multicolumn{3}{|l|}{ All } & \multirow{2}{*}{$\begin{array}{l}\text { Closest } \\
20 \% \text { (Q1) } \\
\text { Mean }\end{array}$} & \multirow{2}{*}{$\begin{array}{l}\text { Furthest } \\
20 \% \text { (Q5) } \\
\text { Mean }\end{array}$} & \multirow{2}{*}{$\begin{array}{l}\text { Q5-Q1 } \\
\text { Difference }\end{array}$} \\
\hline & $\mathrm{n}$ & Mean & SE & & & \\
\hline Total number of prenatal appointments & 1336 & 3.620 & 0.156 & 4.958 & 2.631 & $-2.327^{\star \star}$ \\
\hline Prenatal care (\%) & 1336 & 0.771 & 0.023 & 0.935 & 0.577 & $-0.358^{\star *}$ \\
\hline $\begin{array}{l}\text { Number of weeks of pregnancy at first prenatal appointment } \\
(\%)\end{array}$ & 1074 & 11.795 & 0.369 & 11.123 & 13.342 & $2.219^{*}$ \\
\hline Institutional first prenatal appointment (\%) & 1336 & 0.536 & 0.028 & 0.840 & 0.321 & $-0.519^{\star \star}$ \\
\hline Early and institutional first prenatal appointment (\%) & 1336 & 0.357 & 0.025 & 0.600 & 0.192 & $-0.408^{\star \star}$ \\
\hline Additional prenatal appointments (\%) & 1336 & 0.639 & 0.027 & 0.833 & 0.505 & $-0.328^{\star *}$ \\
\hline Institutional additional prenatal appointments (\%) & 1336 & 0.465 & 0.027 & 0.724 & 0.292 & $-0.433^{\star *}$ \\
\hline Reasons against prenatal care: lack of money (\%) & 431 & 0.414 & 0.032 & 0.407 & 0.437 & 0.030 \\
\hline Reasons against prenatal care: too far (\%) & 431 & 0.671 & 0.034 & 0.619 & 0.629 & 0.010 \\
\hline Reasons against prenatal care: lack of transportation (\%) & 431 & 0.116 & 0.019 & 0.109 & 0.096 & -0.014 \\
\hline Reasons against prenatal care: quality of service (\%) & 431 & 0.084 & 0.022 & 0.091 & 0.032 & -0.059 \\
\hline Reasons against prenatal care: not important (\%) & 431 & 0.150 & 0.023 & 0.053 & 0.185 & $0.132^{*}$ \\
\hline Normal birth with no complications (\%) & 1336 & 0.909 & 0.012 & 0.901 & 0.894 & -0.007 \\
\hline Institutional delivery (\%) & 1336 & 0.537 & 0.028 & 0.692 & 0.345 & $-0.347^{\star \star}$ \\
\hline Had alarming symptom (\%) & 1336 & 0.201 & 0.016 & 0.200 & 0.169 & -0.030 \\
\hline Postnatal care within 2 days of childbirth (\%) & 1336 & 0.464 & 0.026 & 0.628 & 0.277 & $-0.351^{* *}$ \\
\hline Institutional postnatal care (\%) & 1336 & 0.446 & 0.025 & 0.611 & 0.251 & $-0.360^{* *}$ \\
\hline Neonatal exam within 48 hours of birth (\%) & 1336 & 0.534 & 0.027 & 0.690 & 0.353 & $-0.337^{\star *}$ \\
\hline Institutional neonatal exam (\%) & 1336 & 0.518 & 0.026 & 0.682 & 0.326 & $-0.357^{\star *}$ \\
\hline Weighed baby within first week of life (\%) & 1336 & 0.529 & 0.028 & 0.700 & 0.316 & $-0.384^{\star *}$ \\
\hline Child's weight at birth or before 1 week $(\mathrm{kg})$ & 788 & 3.229 & 0.021 & 3.243 & 3.205 & -0.037 \\
\hline Stillbirths or miscarriages (\%) & 1336 & 0.031 & 0.004 & 0.038 & 0.028 & -0.010 \\
\hline
\end{tabular}

Means and standard errors (SE) are estimated considering survey sampling design, including sample weights and clustering effects. Five households missing geographic information are excluded from the distance quintile means.

${ }^{*} \mathrm{p}<0.05,{ }^{* *} \mathrm{p}<0.01$.

$Q$, quintile.

pregnancies per mother was 3.6. Mothers were responsible for about $50 \%$ of household decisions as measured by the empowerment index. Those who lived closest to a health facility (Q1) were significantly wealthier and more educated than those in the farthest distance quintile (Q5) and had slightly fewer pregnancies on average.

\section{Gaps in obstetric care by distance}

In this section, we present mean differences in obstetric care between the top and bottom distance quintiles. As seen in table 2, there are large, significant differences in all prenatal care outcomes between the two groups. Mothers in the furthest 20\% of households (Q5) had 2 prenatal care appointments fewer, on average, and initiated prenatal care over 2 weeks later, than mothers in the closest 20\% (Q1) of households. Additionally, mothers in Q5 were 36 percentage points less likely to have had at least one prenatal care appointment in a hospital, health centre, or clinic compared with mothers in Q1. There were also large differences of about 52 and 41 percentage points, respectively, in attending an institutional first prenatal appointment or an early and institutional first appointment between mothers in each group. The difference in attending more than one appointment was about 33 percentage points and the difference between attending more than one institutional appointment was about 43 percentage points. Reasons for not attending prenatal care were similar between groups, though mothers in Q5 were 13 percentage points more likely to consider prenatal care unimportant compared with mothers in Q1.

Significant gaps in delivery and postnatal care outcomes were also observed. The gap in institutional delivery between Q1 and Q5 was about 35 percentage points. Mothers in Q5 were 35 percentage points less likely to attend a postnatal appointment and 34 percentage points less likely to attend a neonatal exam within 2 days of childbirth compared with mothers in Q1. There were no significant differences in having complications or alarming symptoms during pregnancy. 
The relationship between distance and final health outcomes, including child's birth weight and per cent of stillbirths and miscarriages, is less clear. Of the 784 children who were weighed, there was no significant difference in weight between the two groups. However, there was a 38 percentage-point difference in the likelihood of being weighed between Q1 and Q5. A closer look shows that $97 \%$ of children who were weighed had an institutional delivery, which is much higher than the population average of $53.7 \%$. This suggests that the birth weights of children who were not weighed may be systematically different from those who were. Given this is the case, we cannot adequately assess the relationship between distance and birth weight. We also found no significant differences between distance and per cent of stillbirths and miscarriages.

To assess the relationship between distance and health outcomes for different types of pregnancies, we compared gaps in utilisation between mothers with low-risk and high-risk pregnancies. Low-risk pregnancies are defined as pregnancies in women between 20 and 34 years old, inclusive, who have had three or fewer pregnancies. Highrisk pregnancies include pregnancies in teens, women 35 and older and women who have had more than three pregnancies. Results are presented in online supplementary table A1. Most pregnancies in the population were high-risk (64.3\%), and high-risk mothers had lower rates of utilisation than low-risk mothers. For both low-risk and high-risk mothers, there were significant gaps in utilisation between mothers in Q1 and Q5. The gaps by distance were slightly larger among high-risk mothers, but overall distance did not appear to have significant heterogeneous effects by type of pregnancy.
To understand how health gaps vary with regard to other key determinants, we analysed differences in obstetric care outcomes between the top and bottom distance quintiles by maternal age, education and household wealth. The results are presented in figures 2-4. In general, mothers in Q5 had inferior obstetric care outcomes across all ages, years of education and wealth levels compared with mothers in Q1. However, these gaps, especially those related to care-seeking behaviour, appear to be larger for mothers who were less educated and for mothers who lived in poorer households. Furthermore, the utilisation gap between higher and lower educated mothers was wider in Q5 compared with Q1, suggesting that distance may be a particularly salient barrier for less educated mothers. A similar trend is seen by wealth: differences in wealth among mothers in Q1 did not affect the utilisation of services much, but differences in wealth among mothers in Q5 resulted in stark inequities in utilisation. These finding suggests that mothers who were far from health centres, poor and less educated suffer the most from a lack of access.

\section{Gradients in obstetric care by distance}

In addition to comparing mean differences in obstetric care outcomes for mothers in the top and bottom distance quintiles, we analysed differences in obstetric care outcomes across all five distance quintiles. As seen in figure 5 , there is a strong gradient by distance among all obstetric care outcomes. With every additional quintile further away from a health centre, utilisation and early initiation of obstetric care declined.

We assessed the magnitude and significance of these differences using a regression model with controls for
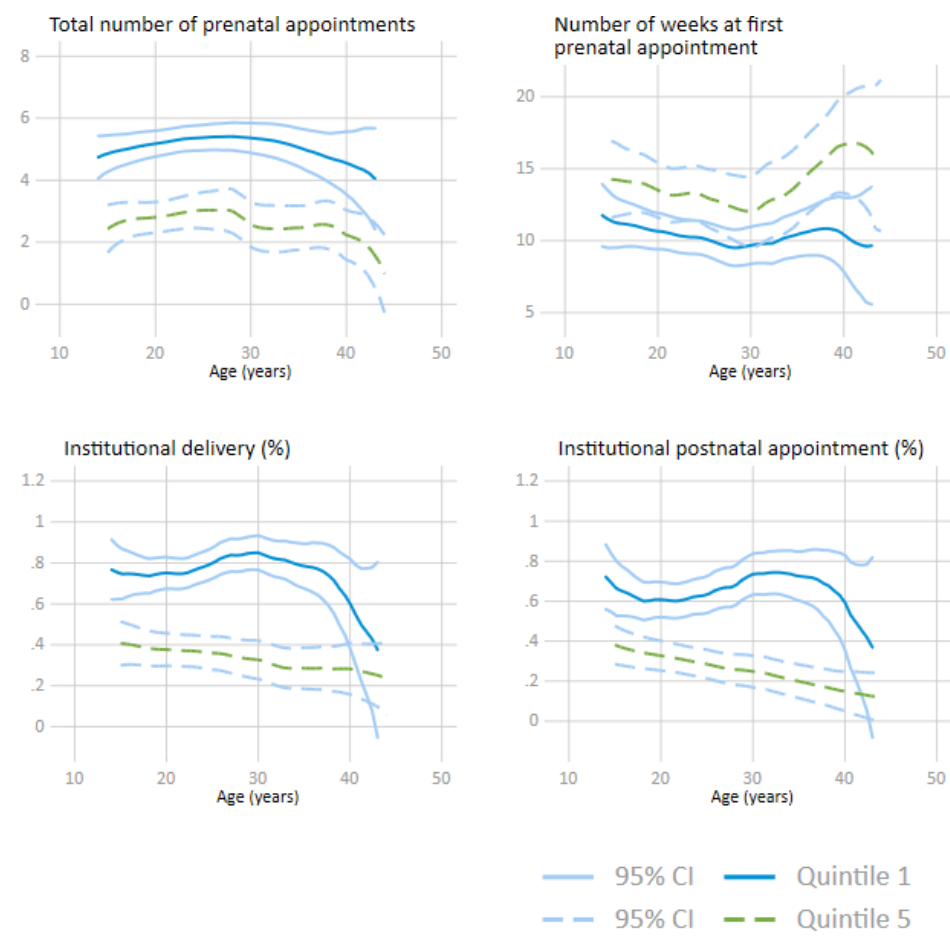
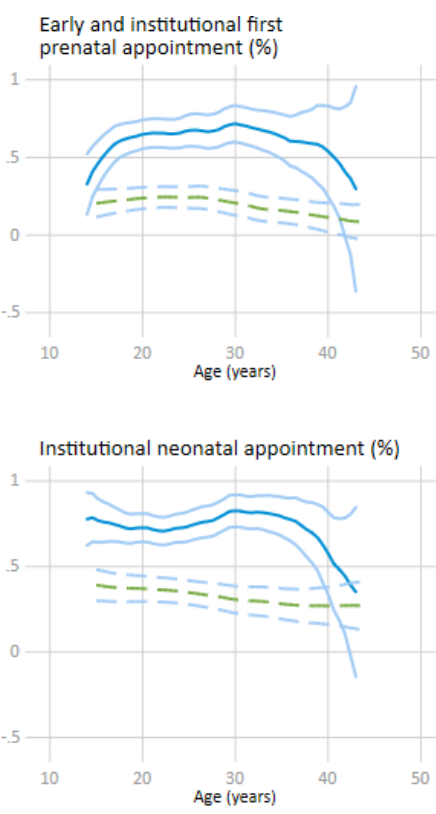

Figure 2 Gaps in obstetric care by distance and maternal age. 

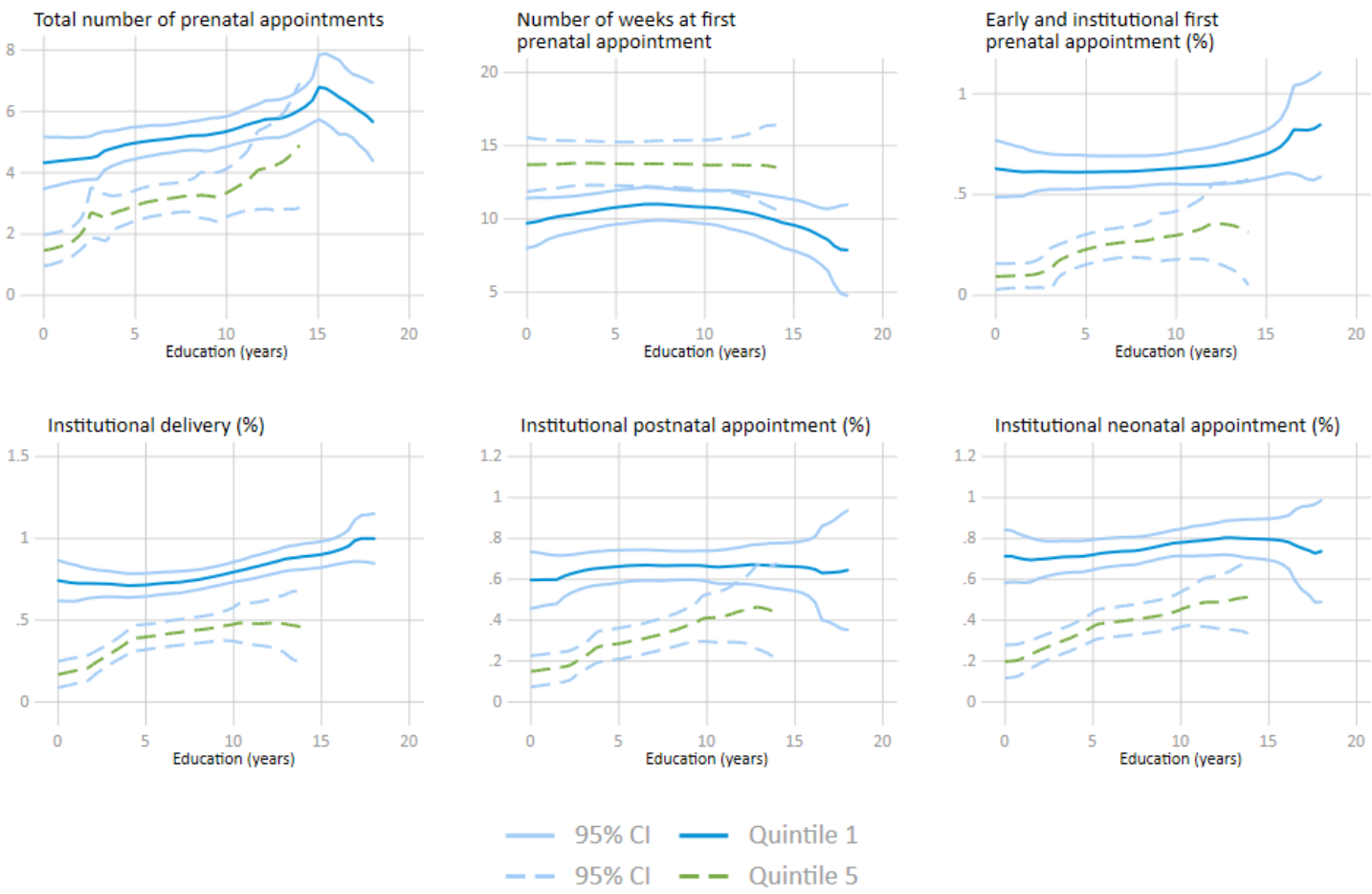

Figure 3 Gaps in obstetric care by distance and maternal education.

wealth, age, education, number of pregnancies and empowerment. As seen in table 3, there are strong and significant effects of distance on almost all outcomes. Compared with mothers in the closest quintile, mothers in Q3 were 8 percentage points less likely to attend at least one prenatal care appointment in a hospital or health centre, a relative difference of about $9 \%$. This gap increased to 27 percentage points for mothers in Q5, a relative difference of $30 \%$. Mothers in Q3 had about
0.6 fewer prenatal care appointments than mothers in Q1; in Q5, the gap increased to 1.5 appointments. The remaining prenatal care outcomes followed the same trend: utilisation and early initiation of prenatal care decreased with every further distance quintile.

Among outcomes related to delivery and the postpartum period, there were strong differences between mothers in Q4 and Q5 with respect to mothers in Q1. Mothers in Q4, for example, were almost 15 percentage points less likely
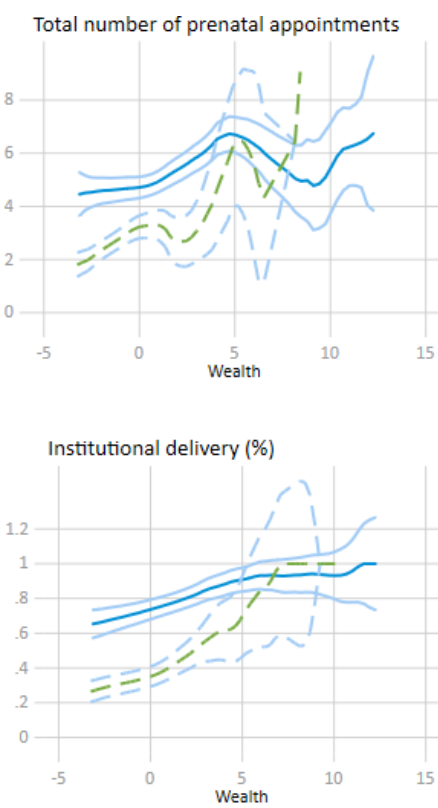
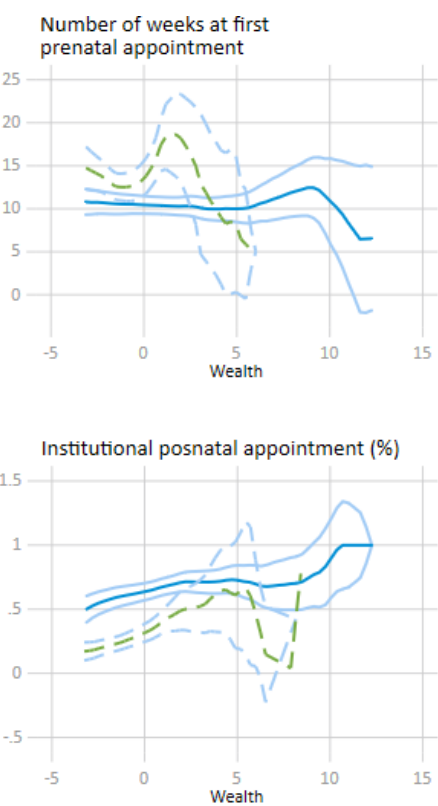

- $95 \% \mathrm{Cl}$ - Quintile 1

- - $95 \% \mathrm{Cl}--$ Quintile 5
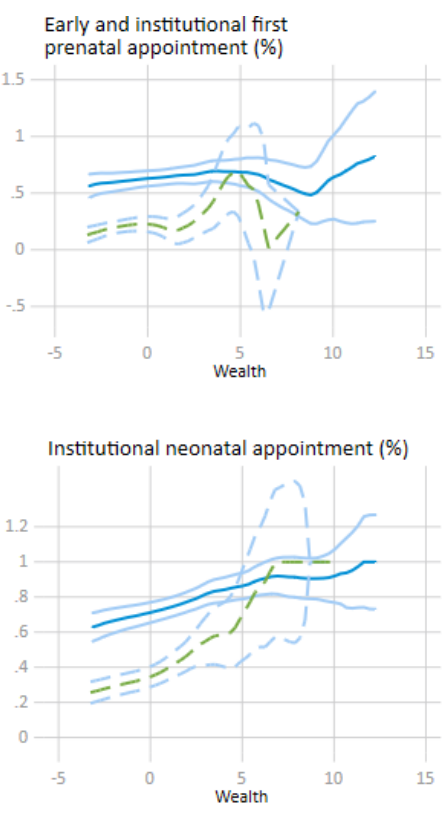

Figure 4 Gaps in obstetric care by distance and household wealth. 

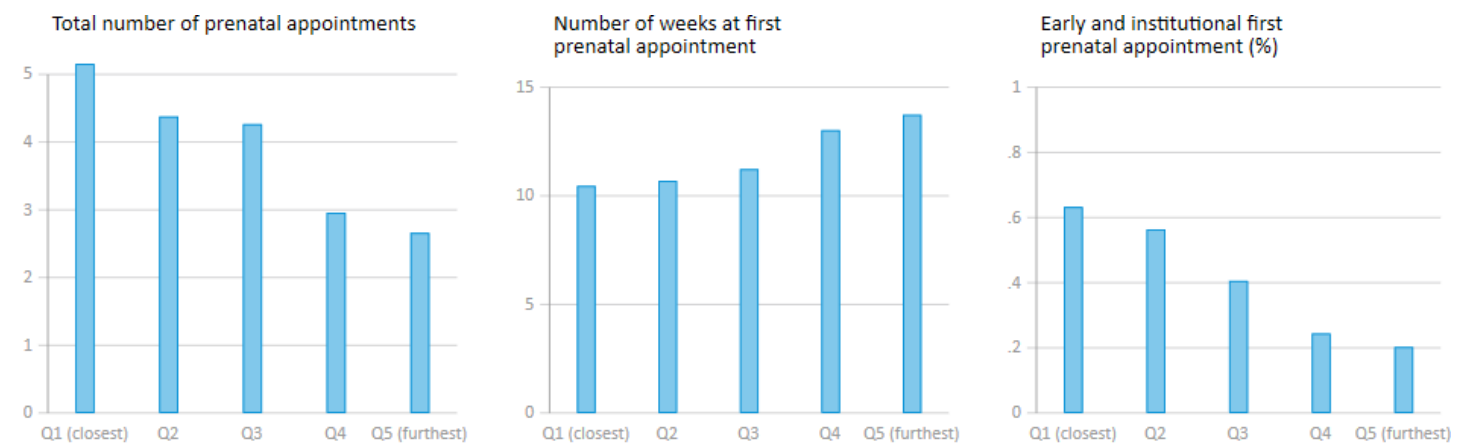

to have an institutional delivery compared with mothers in $\mathrm{Q} 1$, a relative difference of $24 \%$. The difference increased to $34 \%$ in Q5. The difference in postnatal care between mothers in Q4 and Q5 compared with mothers in Q1 was 19 and 25 percentage points, respectively. A similar trend existed among mothers who attended a neonatal exam. We did not find strong evidence for an effect of distance on final health outcomes, though there is a strong relationship between the likelihood of a child being weighed and distance.

\section{DISCUSSION}

The utilisation of care before, during and after childbirth is one of the most effective ways to prevent maternal and infant mortalities. ${ }^{121}$ However, widespread inequities in access to obstetric care in Latin America remain a major challenge to improving maternal and child health in the region. ${ }^{1}$ Indigenous and Afro-descendent populations and women in low-income and rural areas are particularly vulnerable. $^{13}$

This paper builds on a large body of literature surrounding the effect of distance on health outcomes. Numerous studies in developing countries have shown that distance is inversely associated with utilisation of health services. ${ }^{6-12}$ In this paper, we assessed the relationship between distance to an assigned health clinic and the utilisation of obstetric care services among indigenous women in Ngäbe Buglé, the largest indigenous territory in Panama.

We found significant differences in the utilisation of obstetric care between mothers in the closest $20 \%$ of households (Q1) and mothers in the furthest $20 \%$ of households (Q5). More specifically, mothers in Q5 had fewer total appointments, initiated prenatal care later in pregnancy and were less likely to go to a hospital or health centre than mothers in Q1. They were also less likely to have an institutional delivery or to attend a postnatal care appointment. In addition to large differences between the top and bottom distance quintiles, we also found a strong gradient in obstetric care by distance. Utilisation of prenatal care and early initiation of care declined with every additional distance-quintile further away from a health centre, even when controlling for household wealth, maternal age, maternal education, number of pregnancies and empowerment. These findings are consistent with other studies that have found an association between distance and utilisation of health services and suggest that expanding access to healthcare in remote and under-served areas through supply or demand side interventions could be a valuable strategy to improving maternal and child health outcomes in developing countries.

We also found that the disparities in utilisation of services across distance quintiles were much more pronounced for women who are less wealthy and less educated. In fact, for women in Q1, wealth had little effect on utilisation, but for women in Q5, low wealth was a major deterrent to utilisation of obstetric care. This could be because travelling to a health centre from a farther distance requires a higher economic cost. For women in Q1, for example, the cost of transportation and the time spent to get to an appointment an average of $4.5 \mathrm{~km}$ away is substantially lower than for women in Q5, who had to travel an average of $50 \mathrm{~km}$. In this sense, women who are poor and less 
Table 3 Gradients in obstetric care by distance (OLS regression)

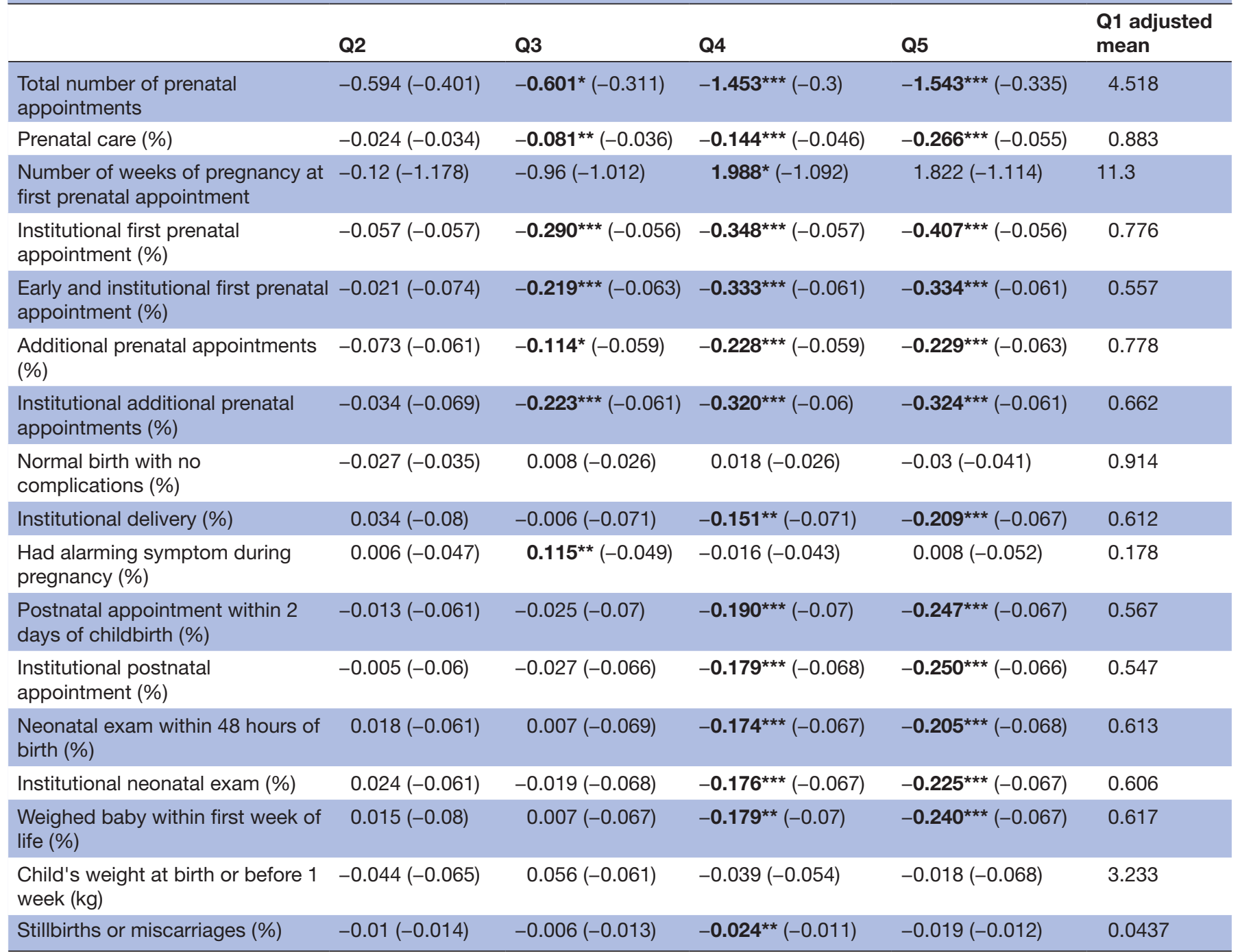

Estimated coefficients on Q2-Q5 for each outcome are from a separate OLS regression (equation (1)).

Means and standard errors (SE) are estimated considering survey sampling design, including sample weights and clustering effects. Five households missing geographic information are excluded from the distance quintile means. All models control for wealth (estimated with principal component analysis), age (years), education (years), number of pregnancies and empowerment.

Q1 is the reference category. Q1 adjusted means are estimated at mean values of the control variables.

${ }^{*} \mathrm{p}<0.1,{ }^{* *} \mathrm{p}<0.05,{ }^{* * *} \mathrm{p}<0.01$.

$\mathrm{Q}$, quintile.

educated suffered the most from being far from health facilities. The upfront costs required to get to appointments may be a significant barrier to accessing necessary care. In fact, the two most frequently reported reasons given for not accessing prenatal care were lack of money $(41.4 \%)$ and health services being too far $(67.1 \%)$.

To address the disparities in obstetric care utilisation for populations that are far from established health services, policymakers may consider supply and demand side interventions. Supply side alternatives such as the expansion of facility-based health centres or mobile clinics may be cost-effective solutions for more densely populated areas. However, in the context of Ngäbe Buglé, providing universal access to formal health services within a distance of $4.5 \mathrm{~km}$ (the average of Q1 in our sample) is unlikely to be cost-effective or feasible, as it would require large infrastructure investments and staffing of health personnel to serve a limited number of households in remote and highly dispersed rural areas. In these contexts, demand-side interventions such as conditional cash transfers or transportation vouchers could be alternative policy options to boost obstetric care utilisation. Conditional cash transfers, which condition monetary payments on health service utilisation, have been shown to effectively increase the utilisation of health services, including in rural and indigenous contexts. ${ }^{22-25}$ Transfer amounts could be set in relation to distance, with higher amounts in more distant communities to compensate for the opportunity cost of time and higher transportation costs. Further research to be conducted through a 
prospective randomised trial is required to measure the effectiveness of conditional cash transfers on obstetric care utilisation in the context of Ngäbe Buglé.

\section{Study strengths and limitations}

A major advantage of our study is our novel approach to calculating distances. While most studies use linear distances, which are unable to account for physical barriers and often underestimate the true distance, our study utilised the Dijkstra algorithm to approximate the distance of viable routes. In QGIS, we determined the shortest route from every household to its assigned health clinic - using a network of roads, rivers, canals and other polylines-and measured the associated distance. Compared with linear paths, this measure of distance is likely to be more accurate, especially in an extremely mountainous and remote area, where there are many physical barriers and limited infrastructure. Another advantage of this paper is our sample population. Our data includes utilisation and health outcome measures for a representative sample of 1336 indigenous mothers. While health disparities research is growing, there are still gaps in data collection and analysis of the health status of indigenous populations. Given indigenous people make up around $8 \%$ of the population in the region- 45 million people in total-and often have much worse health outcomes compared with non-indigenous people, they are an important population to consider when making policy and programme decisions. ${ }^{26}$

A limitation of this study is that our analysis considers only distances between the household and its assigned health centre, while existing evidence suggests that women may travel to more distant facilities if they are perceived to be of higher quality. ${ }^{27}$ However, since the assigned health centre in Ngäbe Buglé is also the closest available health service, our ranking of households by distance quintile is likely to preserve the relative ordering of distance even if more distant facilities were also included in the analysis. Additionally, while we use a sophisticated method for calculating distances, there are possible inaccuracies. The study area is extremely remote, and the road network is sparse, so it is possible that some of the routes taken by families are not included in Open Street Maps. Another limitation is that outcome measures are based on selfreporting, which may introduce some measurement error relative to medical records. However, only mothers who gave birth within the last 12 months are included in the sample to help minimise recall bias.

\section{CONCLUSIONS}

This paper highlights the important relationship between distance to a health facility and the utilisation of obstetric care among indigenous women in Panama. The results presented in this paper provide evidence on a key barrier to health seeking behaviour and will inform the design of programme that may help reduce these barriers, including cash transfers, vouchers and the expansion of health infrastructure, among others. Rigorous testing of these interventions will be required to determine the most cost-effective types of interventions for reducing barriers related to distance, and, ultimately, improving maternal and child health outcomes.

Acknowledgements We are grateful to the Ministry of Health in Panama, in particular to Dr. Tania Chung, for granting access to the baseline survey of PN-L1068 used for this study. We thank the staff at ECONSUL Consulting group, Carlos Alviar, Mario Navarrete and Fernando Ferreira for their work on the collection of the survey. All opinions in this paper are those of the authors and do not necessarily represent the views of the Government of Panama or the Inter-American Development Bank, their Executive Directors or the governments they represent.

Contributors Conceived and designed the study: PA, SM, LP. Wrote the paper: PA, SM and SW. Discussed, critically revised and approved the study protocol: PA, SM, LP. Responsible for the organisation and conduct of the study: SM, LP, ES-M. Supervised the study: PA, SM. Responsible for the statistical analysis: PA, SW, SM. Contributed to data analysis: SW. Drafted the first version of the report: SM, SW. Elaborated, discussed and approved the final version of the paper for publication: PA, SM, LP, ES-M and SW.

Funding The survey used in this study was financed by the Ministry of Health in Panama with support from the Inter-American Development Bank projects PN-L1068 and PN-L1115. All authors were IDB staff at the time of the study's conception and implementation. The opinions in this paper are those of the authors and do not necessarily represent the views of the Ministry of Health of Panama, of the Government of Panama, or of the Inter-American Development Bank, its Executive Directors, or the governments they represent.

Map disclaimer The depiction of boundaries on this map does not imply the expression of any opinion whatsoever on the part of BMJ (or any member of its group) concerning the legal status of any country, territory, jurisdiction or area or of its authorities. This map is provided without any warranty of any kind, either express or implied.

Competing interests None declared.

Patient consent for publication Not required.

Ethics approval This study analysed primary survey data collected as part of the evaluation of the Program for Community Support in Panama. The study, including the baseline survey, was approved by the National Committee of Research BioEthics of Panama (IRB approval number EC-CNBI-2016-05-24) and was registered in the AEA RCT Registry (RCT ID AEARCTR-0001751). All subjects provided informed consent prior to the interview, and data were de-identified of personally identifiable information prior to analysis.

Provenance and peer review Not commissioned; externally peer reviewed.

Data availability statement Data are available upon reasonable request. All nonidentifiable data will be made available through the Inter-American Development Bank's publications website following publication of the randomised trials associated with the baseline data used for these analyses.

Open access This is an open access article distributed in accordance with the Creative Commons Attribution Non Commercial (CC BY-NC 4.0) license, which permits others to distribute, remix, adapt, build upon this work non-commercially, and license their derivative works on different terms, provided the original work is properly cited, appropriate credit is given, any changes made indicated, and the use is non-commercial. See: http://creativecommons.org/licenses/by-nc/4.0/.

ORCID iD

Sebastian Martinez http://orcid.org/0000-0002-7651-6674

\section{REFERENCES}

1 World Health Organization. Maternal mortality: key facts, 2018. Available: https://www.who.int/news-room/fact-sheets/detail/ maternal-mortality

2 World Health Organization. New guidelines on antenatal care for a positive pregnancy experience, 2016. Available: https://www.who.int/ reproductivehealth/news/antenatal-care/en/

3 Regional Task Force for the Reduction of Maternal Mortality (GTR). Overview of the situation of maternal morbidity and mortality: Latin 
America and the Caribbean, 2017. Available: https://lac.unfpa.org/ sites/default/files/pub-pdf/MSH-GTR-Report-Eng.pdf

4 Committee to Study the Prevention of Low Birthweight, Division of Health Promotion and Disease Prevention, Institute of Medicine. Preventing low birthweight: the effectiveness of prenatal care. Washington, DC: National Academies Press (US), 1985. https://www. ncbi.nlm.nih.gov/books/NBK214461/

5 Debiec KE, Paul KJ, Mitchell CM, et al. Inadequate prenatal care and risk of preterm delivery among adolescents: a retrospective study over 10 years. Am J Obstet Gynecol 2010;203:122.e1-122.e6.

6 Yasuoka J, Nanishi K, Kikuchi K, et al. Barriers for pregnant women living in rural, agricultural villages to accessing antenatal care in Cambodia: a community-based cross-sectional study combined with a geographic information system. PLoS One 2018;13:e0194103.

7 Feikin DR, Nguyen LM, Adazu K, et al. The impact of distance of residence from a peripheral health facility on pediatric health utilisation in rural Western Kenya. Trop Med Int Health 2009;14:54-61.

8 Adane M, Mengistie B, Mulat W, et al. Utilization of health facilities and predictors of health-seeking behavior for under-five children with acute diarrhea in slums of Adis Ababa, Ethiopia: a community-based cross-sectional study. J Health Popul Nutr 2017;36.

9 Gething PW, Noor AM, Zurovac D, et al. Empirical modelling of government health service use by children with fevers in Kenya. Acta Trop 2004;91:227-37.

10 Buor D. Analysing the Primacy of distance in the utilization of health services in the Ahafo-Ano South district, Ghana. Int J Health Plann Manage 2003;18:293-311.

11 Stock R. Distance and the utilization of health facilities in rural Nigeria. Soc Sci Med 1983;17:563-70.

12 Abbas AA, Walker GJ. Determinants of the utilization of maternal and child health services in Jordan. Int J Epidemiol 1986;15:404-7.

13 Kelly C, Hulme C, Farragher T, et al. Are differences in travel time or distance to healthcare for adults in global North countries associated with an impact on health outcomes? A systematic review. BMJ Open 2016;6:e013059.

14 Instituto Nacional de Estadística y Censo (INEC). Población en La Republica, POR sexo, según Provincia, Comarca indígena y grupos de edad: Censo, 2010. Available: https://www.contraloria.gob.pa/ inec/Publicaciones/Publicaciones.aspx?ID_SUBCATEGORIA=59\&ID_ PUBLICACION=360\&ID_IDIOMA =1\&ID_CATEGORIA $=13$
15 Moreno OA, Guerra JA, Diéguez J, Ministerio de Economía y Finanzas. Índice de Pobreza multidimensional de Panamá-Año 2018, 2018. Available: https://www.mef.gob.pa/wp-content/uploads/2018/ 09/Informe-del-\%C3\%8Dndice-de-Pobreza-Multidimensional-dePanam\%C3\%A1-2018.pdf

16 Acevedo P, Alviar C, Chung T, et al. Evaluación de impacto experimental del programa de apoyos comunitarios (PACO) en Panamá. IDB-TN-01517. IDB-TN-01517. Nota técnica, 2018.

17 Instituto Nacional de Estadística y Censo de Panamá (INEC). Available: https://www.contraloria.gob.pa/inec/

18 Fernandez D. Estudio de barreras a la oferta y demanda de servicios de salud en poblacionesindígenas en Panamá. Mimeo BID, 2012.

19 Dijkstra EW. A note on two problems in connexion with graphs. Numer Math 1959;1:269-71.

20 QGIS Python API. Class: QgsGraphAnalyzer. Available: https://qgis. org/pyqgis/master/analysis/QgsGraphAnalyzer.html\#qgis.analysis. QgsGraphAnalyzer.dijkstra

21 Institute of Medicine (US) Committee on Improving Birth Outcomes, Bale JR, Stoll BJ, Lucas AO, eds. Improving birth outcomes: meeting the challenge in the developing world. Washington, DC: National Academies Press, 2003.

22 Fiszbein A, Norbert S. Conditional cash transfers: reducing present and future poverty. Washington, DC: World Bank, 2009.

23 Lim SS, Dandona L, Hoisington JA, et al. India's Janani Suraksha Yojana, a conditional cash transfer programme to increase births in health facilities: an impact evaluation. Lancet 2010;375:2009-23.

24 Ahmed S, Khan MM. A maternal health voucher scheme: what have we learned from the demand-side financing scheme in Bangladesh? Health Policy Plan 2011;26:25-32.

25 Celhay P, Martinez S, Johannsen J, et al. Can small incentives have large payoffs? health impacts of a cash transfer program in Bolivia. Econ Dev Cult Change. (forthcoming).

26 United Nations Development Programme (UNDP). Indigenous peoples. Available: http://www.latinamerica.undp.org/content/ rblac/en/home/ourwork/democratic-governance/politicalparticipation-and-inclusion/citizen-democracy--analysis--advocacy-.htm

27 Hernandez B, Colombara DV, Gagnier MC, et al. Barriers and facilitators for institutional delivery among poor Mesoamerican women: a cross-sectional study. Health Policy Plan 2017;32:769-80. 